\title{
Evaluation of the Precision of Magnetic Resonance Phase Velocity Mapping for Blood Flow Measurements
}

\author{
George P. Chatzimavroudis \\ Cleveland State University \\ John N. Oshinski \\ Emory University \\ Robert H. Franch \\ Emory University \\ Peter G. Walker \\ University of Leeds
}

Ajit P. Yoganathan

Georgia Institute of Technology and Emory University

Follow this and additional works at: https://engagedscholarship.csuohio.edu/encbe_facpub

- next page for additional authors

Part of the Brochemical and Biomolecular Engineering Commons, and the Biomedical Engineering and

Bioengineering Commons

How does access to this work benefit you? Let us know!

\section{Repository Citation}

Chatzimavroudis, George P.; Oshinski, John N.; Franch, Robert H.; Walker, Peter G.; Yoganathan, Ajit P.; and Pettigrew, Roderic I., "Evaluation of the Precision of Magnetic Resonance Phase Velocity Mapping for Blood Flow Measurements" (2001). Chemical \& Biomedical Engineering Faculty Publications. 27.

https://engagedscholarship.csuohio.edu/encbe_facpub/27

This Article is brought to you for free and open access by the Chemical \& Biomedical Engineering Department at EngagedScholarship@CSU. It has been accepted for inclusion in Chemical \& Biomedical Engineering Faculty Publications by an authorized administrator of EngagedScholarship@CSU. For more information, please contact library.es@csuohio.edu. 


\section{Authors}

George P. Chatzimavroudis, John N. Oshinski, Robert H. Franch, Peter G. Walker, Ajit P. Yoganathan, and Roderic I. Pettigrew 
Journal of Cardiovascular Magnetic Resonance ${ }^{\circledR}, 3(1), 11-19$ (2001)

\title{
Evaluation of the Precision of Magnetic Resonance Phase Velocity Mapping for Blood Flow Measurements
}

\author{
George P. Chatzimavroudis, ${ }^{1}$ John N. Oshinski, ${ }^{2}$ \\ Robert H. Franch, ${ }^{3}$ Peter G. Walker, ${ }^{4}$ \\ Ajit P. Yoganathan, ${ }^{5}$ and Roderic I. Pettigrew ${ }^{2}$ \\ ${ }^{1}$ Department of Chemical Engineering, Cleveland State University, \\ Cleveland, Ohio \\ ${ }^{2}$ Frederik Philips Magnetic Resonance Research Center, Department of \\ Radiology, Emory University School of Medicine, Atlanta, Georgia \\ ${ }^{3}$ Division of Cardiology, Department of Medicine, Emory University School \\ of Medicine, Atlanta, Georgia \\ ${ }^{4}$ Department of Mechanical Engineering, University of Leeds, Leeds, UK \\ ${ }^{5}$ Department of Biomedical Engineering, Georgia Institute of Technology \\ and Emory University, Atlanta, Georgia
}

\begin{abstract}
Evaluating the in vivo accuracy of magnetic resonance phase velocity mapping (PVM) is not straightforward because of the absence of a validated clinical flow quantification technique. The aim of this study was to evaluate PVM by investigating its precision, both in vitro and in vivo, in a 1.5 Tesla scanner. In the former case, steady and pulsatile flow experiments were conducted using an aortic model under a variety of flow conditions (steady: 0.1-5.5 L/min; pulsatile: 10-75 mL/cycle). In the latter case, PVM measurements were taken in the ascending aorta of ten subjects, seven of which had aortic regurgitation. Each velocity measurement was taken twice, with the slice perpendicular to the long axis of the aorta. Comparison between the measured and true flow rates and volumes confirmed the high accuracy of PVM in measuring flow in vitro $(p>0.85)$. The in vitro precision of PVM was found to be very high
\end{abstract}

Address correspondence to Roderic I. Pettigrew, M.D., Department of Radiology, Emory University School of Medicine, 1364 Clifton Rd., Atlanta, GA 30322. E-mail: rpettig@emory.edu 
(steady: $y=1.00 x+0.02, r=0.999 ;$ pulsatile: $y=0.98 x+0.72, r=0.997 ; x$ : measurement \#1, y: measurement \#2) and this was confirmed by Bland-Altman analysis. Of great clinical significance was the high level of the in vivo precision $(y=1.01 x-0.04, r=0.993)$, confirmed statistically $(p=1.00)$. In conclusion, PVM provides repeatable blood flow measurements. The high in vitro accuracy and precision, combined with the high in vivo precision, are key factors for the establishment of PVM as the "gold-standard" to quantify blood flow.

KEY WORDS: Accuracy; Aortic regurgitation; Flow quantification; Magnetic resonance; Magnetic resonance phase velocity mapping; Precision

\section{INTRODUCTION}

Magnetic resonance phase velocity mapping (PVM) is a technique that has been widely used clinically to measure blood flow. Modern PVM was invented in 1982 by Moran (1). Since then, there have been many in vitro and clinical studies evaluating PVM as a technique for flow characterization or quantification. In vitro, the accuracy of PVM was found to be consistently very high with errors of less than 10\% (2-5). Early animal studies (6) also showed a good correlation between the flow rates measured with PVM and conventional flow meters. PVM measurements in humans correlated with conventional velocimetric techniques, such as Doppler ultrasound, and with other nonvelocimetric diagnostic techniques (2,7-12).

The clinical application of PVM to measure blood flow has been extensive $(8,9,13-17)$. The technique has provided invaluable information about the two-dimensional velocity profiles in the ascending aorta, the blood flow in the venae cavae in patients with right heart disease, the ventricular stroke volumes, the blood flow in the pulmonary artery, the arterial and venous flow, helical and retrograde secondary flow patterns in the aortic arch, and the antegrade and retrograde flow in the entire aorta and in arteries supplying muscles.

Despite the accuracy found in vitro, evaluation of the reliability of PVM in humans is not straightforward because of the absence of a validated clinical technique to measure flow through a vessel with which PVM could be compared. Clinical correlations of PVM with Doppler ultrasound do not prove that PVM is accurate in vivo because Doppler can be affected by a number of technical factors, such as the beam angle, and thus cannot be used as the technique of reference. In addition, currently Doppler can only provide the velocity profile across a single line of the cross section of a vessel, whereas PVM acquires the entire cross-sectional velocity profile. This is very important for reliable flow rate quantification.
In the absence of a gold-standard in vivo technique to measure blood flow, PVM cannot be evaluated yet for its clinical accuracy. An indirect alternative approach, which could show the reliability of PVM clinically, is to evaluate its precision. Precision is the repeatability of PVM-in other words, whether successive measurements taken at the same location in a subject agree with each other. Dulce et al. (10) performed an early PVM repeatability study, taking measurements in the ascending aorta of patients with aortic regurgitation, twice at the same location in each patient, with promising results $(r>0.97)$.

The present study aims to investigate systematically the precision of magnetic resonance phase velocity mapping, both in vitro and in vivo. In vitro studies under steady and pulsatile flow conditions will serve as the reference data for the level of precision to be achieved clinically. Subsequently, clinical measurements will evaluate the in vivo precision of PVM. Combination of the in vivo with the in vitro data will provide important information about the clinical precision and reliability of PVM.

\section{METHODS}

\section{In Vitro Measurements}

Steady and pulsatile flow experiments were conducted using a variety of flow rates. PVM measurements were taken in a compliant silicone aortic model (ID $=25 \mathrm{~mm}$ ), which included the aortic root with the sinuses of Valsalva and a stentless porcine aortic valve (Medtronic, Inc., Minneapolis, MN). The experiments reproduced the flow rates observed during diastole in the ascending aorta in patients with aortic regurgitation (AR). Regurgitation conditions were reproduced by mounting a tube between the leaflets of the valve, preventing their complete closure. Water was used as the blood analog fluid for simplicity. Although the viscosity of water is approximately 3.5 times 
lower than that of blood, its use in this study is justified by the fact that, under the flow conditions used, flow is predominantly driven by inertia compared to viscous mechanisms. The aortic model was mounted inside a large water-filled container in order to provide a stronger MR signal.

In the first part of the in vitro study, steady flow conditions were generated and the flow rate was measured with a calibrated rotameter. In the second part of the in vitro study, pulsatile flow was generated by a computer-controlled piston pump (SuperPump, SPS 3891 Vivitro Systems Inc., Victoria, BC, Canada). The flow rate waveform was measured with a brass transit time ultrasonic flow probe (24N in-line, Transonic Systems Inc., Ithaca, NY), located $20 \mathrm{~cm}$ downstream of the PVM measurements location. The data was acquired by a singlechannel flowmeter (T-108, Transonic Systems Inc.). The flow waveform was recorded on a PC by digitizing the analog signal from the flowmeter with an A/D board (NB-MIO-16, National Instruments Inc., Austin, TX), using the LabVIEW software (Version 3.0, National Instruments, Inc.). The flow conditions of the in vitro experiments can be seen in Table 1 (steady flow) and Table 2 (pulsatile flow).

The entire flow loop was placed in a 1.5 Tesla scanner (NT Gyroscan, Philips Medical Systems, Best, The Netherlands). Initially, a coronal scout spin-echo image was acquired [slice thickness (ST): 7-mm; field of view (FOV): $300 \mathrm{~mm}$; echo time (TE): $25 \mathrm{~ms}$; repetition time (TR): $432 \mathrm{~ms}$ for steady flow, $1000 \mathrm{~ms}$ for pulsatile flow; matrix size: $256 \times 256$; ECG triggering for pulsatile flow].

\section{Table 1}

True and PVM-Measured Flow Rates Under Steady Flow Conditions

\begin{tabular}{lccccc}
\hline $\begin{array}{l}\text { True } \\
(\mathrm{L} / \mathrm{min})\end{array}$ & $\begin{array}{c}\text { Measured } \\
\text { Series 1 } \\
(\mathrm{L} / \mathrm{min})\end{array}$ & $\begin{array}{c}\text { Measured } \\
\text { Series 2 } \\
(\mathrm{L} / \mathrm{min})\end{array}$ & $\begin{array}{c}\text { True } \\
(\mathrm{L} / \mathrm{min})\end{array}$ & $\begin{array}{c}\text { Measured } \\
\text { Series 1 } \\
(\mathrm{L} / \mathrm{min})\end{array}$ & $\begin{array}{c}\text { Measured } \\
\text { Series 2 } \\
(\mathrm{L} / \mathrm{min})\end{array}$ \\
\hline 0.200 & 0.224 & 0.260 & 2.200 & 2.280 & 2.312 \\
0.300 & 0.257 & 0.301 & 2.300 & 2.371 & 2.483 \\
0.350 & 0.298 & 0.362 & 2.700 & 2.671 & 2.703 \\
0.400 & 0.334 & 0.346 & 2.800 & 2.802 & 2.894 \\
0.450 & 0.425 & 0.345 & 4.000 & 4.136 & 4.101 \\
0.500 & 0.436 & 0.494 & 4.200 & 4.213 & 4.213 \\
1.100 & 1.069 & 1.031 & 4.300 & 4.292 & 4.284 \\
1.200 & 1.165 & 1.179 & 5.700 & 5.698 & 5.694 \\
1.700 & 1.612 & 1.674 & 5.800 & 5.718 & 5.806 \\
1.800 & 1.763 & 1.735 & & & \\
\hline
\end{tabular}

Table 2

\begin{tabular}{|c|c|c|}
\hline $\begin{array}{l}\text { True } \\
\text { (mL/cycle) }\end{array}$ & $\begin{array}{c}\text { Measured } \\
\text { Series } 1 \\
(\mathrm{~mL} / \text { cycle })\end{array}$ & $\begin{array}{c}\text { Measured } \\
\text { Series } 2 \\
(\mathrm{~mL} / \text { cycle })\end{array}$ \\
\hline 27.00 & 26.67 & 26.61 \\
\hline 35.00 & 35.19 & 34.86 \\
\hline 37.00 & 37.80 & 37.02 \\
\hline 48.00 & 47.86 & 47.63 \\
\hline 53.00 & 53.26 & 53.95 \\
\hline 57.00 & 57.16 & 57.65 \\
\hline 75.00 & 75.11 & 73.08 \\
\hline
\end{tabular}

The aortic model was identified on the scout image (Fig. 1) and, for each one of the different flow conditions used, a transverse velocity-encoded gradient-echo image acquisition was performed $2.0 \mathrm{~cm}$ beyond the sinotubular junction of the model (ST: $5 \mathrm{~mm}$; FOV: $200 \mathrm{~mm}$; TR: $30 \mathrm{~ms}$; TE: 6-9 ms; flip angle: $35^{\circ}$; matrix size: $128 \times 128$; pixel size: $1.56 \times 1.56 \mathrm{~mm})$. In this way, the distance between the slice and the regurgitant aortic valve was long enough to exclude flow acceleration and other complex flows from the region of the velocity measurements. Flow acceleration and complex flows (turbulence, intense

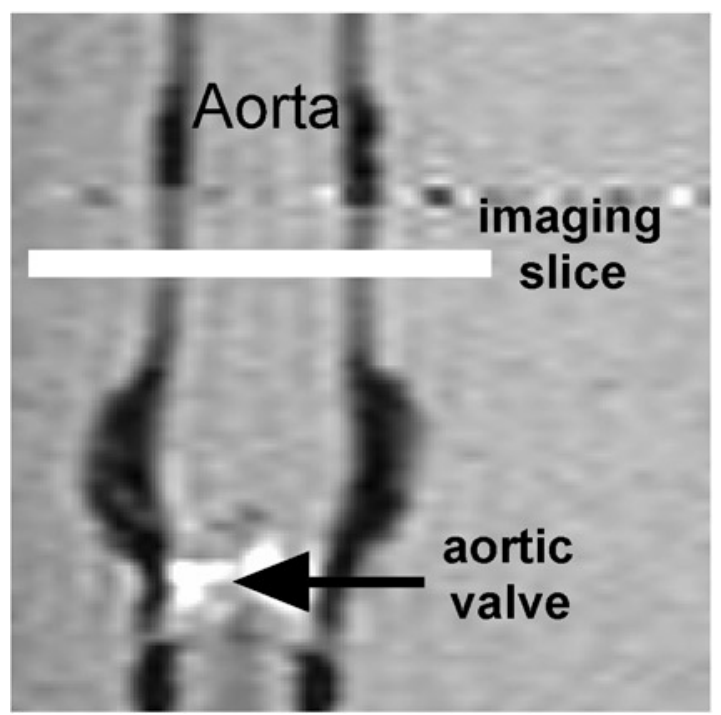

Figure 1. Scout spin-echo image showing the in vitro aortic model and the slice location for the velocity measurements. 
vortices) cause signal loss, as usually seen in the vicinity of the regurgitant aortic valve clinically. A range (25$500 \mathrm{~cm} / \mathrm{s}$ ) of velocity encoding values (VENC) was used, depending on the studied flow rate to adjust the velocity sensitivity of PVM. In steady flow, a modulus and a phase image were acquired for each acquisition. In pulsatile flow, retrospective ECG gating was used to acquire 20 time phases per cycle (same imaging parameters as in steady flow).

Each acquisition (in both steady and pulsatile flow) was performed twice. After the first measurement, the flow was reduced until it reached "zero." Then, it was readjusted to its initial value.

\section{In Vivo Measurements}

To evaluate the in vitro results clinically, measurements were taken in the ascending aorta of ten subjects. Seven of these subjects had AR (severity grades I, II, and III, as previously assessed by angiography and echocardiography) and three were healthy volunteers. The entire aortic flow throughout the cardiac cycle was measured in the healthy subjects, using a high VENC $(300 \mathrm{~cm} / \mathrm{s})$. In the seven patients with $\mathrm{AR}$, the measurements focused only on the diastolic part of the cardiac cycle, because systolic flow turbulence caused signal loss in the ascending aorta. This turbulence was the result of either increased systolic forward flow (a compensatory mechanism in patients with $\mathrm{AR}$ ), or concomitant AR and aortic stenosis. A lower VENC $(50 \mathrm{~cm} / \mathrm{s})$ was used, because the peak reverse regurgitant flow velocity in the ascending aorta during diastole is significantly lower than the systolic aortic velocity. The aortic root was located in the gradient-echo scout image (Fig. 2). The sinotubular junction was identified and PVM measurements (ST: $5 \mathrm{~mm}$; FOV: $250 \mathrm{~mm}$; TR: $14-30 \mathrm{~ms}$; TE: $6-9 \mathrm{~ms}$; flip angle: $35^{\circ}$; matrix size: $128 \times 128$ ) were taken perpendicular to the long axis of the aorta approximately $2.0 \mathrm{~cm}$ beyond the sinotubular junction in order to be relatively far from the aortic valve. The velocity-encoded acquisition required approximately $4 \mathrm{~min}$, depending on the heart rate of the subject. Retrospective ECG gating was used to provide 13-18 phases during the cardiac cycle. These measurements were performed twice for each subject. The second measurement was taken within a few minutes after the first one. The heart rate was continuously monitored during these successive PVM acquisitions, and only measurements performed under similar conditions with regard to heart rate were accepted for analysis in this study.

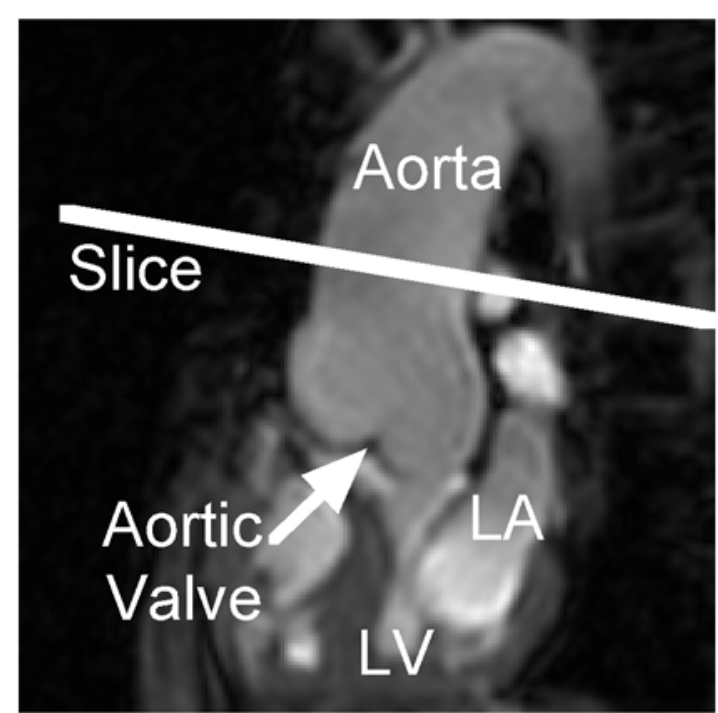

Figure 2. Scout gradient-echo image showing the aortic root of a subject and the slice location for the velocity measurements.

\section{Data and Statistical Analysis}

Although the scanner used in this study is designed to eliminate eddy currents, the phase images were processed to remove any phase offsets present, as described in our previous studies $(4,18)$. Subsequently, the crosssection of the aorta was identified and selected separately on each modulus image of the cycle (based on the higher signal intensity of flowing blood in the aorta) and the selection was applied to the phase images. The phase was converted to velocity, based on the linearity between MR signal phase and velocity, and integration of this velocity over the cross-sectional area of the aorta yielded the flow rate. In the pulsatile flow in vitro cases and in the in vivo cases, the flow volume was calculated by integrating the instantaneous flow rate curve over the time period selected. To calculate the flow volumes, the flow waveform was integrated over the entire cardiac cycle in the case of the healthy subjects, whereas only the diastolic part of the cycle was considered in the case of AR patients.

The nonparametric Mann-Whitney test (19) and BlandAltman analysis (20) were applied using the Minitab statistical analysis software (Version 10, Minitab, Inc., State College, PA) to determine the repeatability of the measurements. It should be pointed out that, for this type of data, nonparametric statistical analysis is preferred over the usual $t$-test, because the amount of data in each case is not large enough to ensure reliability of the $t$-test. 


\section{RESULTS}

\section{In Vitro}

Tables 1 and 2 contain all the in vitro PVM results and the "true" flow rates and volumes, as measured via the rotameter and the flow probe. The accuracy of both the steady and pulsatile flow measurements was excellent, as confirmed by Mann-Whitney tests ( $p>0.85$ in all cases).

Figure 3 shows the correlation between the two series of the steady flow measurements. As seen, an excellent correlation $\left(y=1.00 x+0.02, \quad r^{2}=0.999\right.$, $\mathrm{SDE}=0.051 \mathrm{~L} / \mathrm{min}, p=0.00$ ) was found throughout the entire range of flow rates studied. The agreement between the two series of measurements is also seen from the Bland-Altman analysis plot (Fig. 4) where the mean of their difference is very close to zero $(-0.024 \mathrm{~L} / \mathrm{min})$ and the standard deviation of this difference is small $(0.05 \mathrm{~L} / \mathrm{min})$. The scattering of the differences between the two series is small and random throughout the flow rate range used. Statistical analysis with a Mann-Whitney test confirmed that there is no statistically significant difference between the two series ( $p=0.87$, confidence interval $(\mathrm{CI})$ : $[-1.318,1.266 \mathrm{~L} / \mathrm{min}]$.

Similar to the steady-state situation, the pulsatile flow data showed great agreement between the two series of measurements. The correlation found with regression analysis (Fig. 5) between the two series

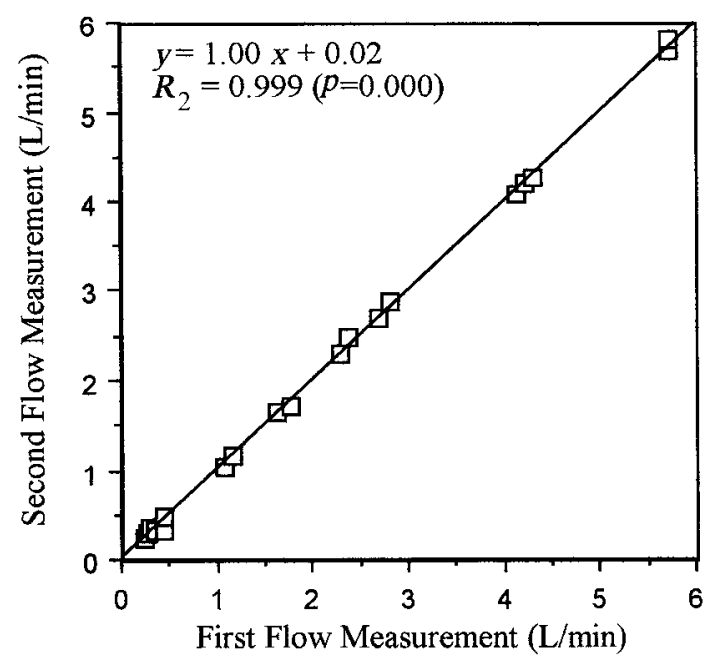

Figure 3. Correlation between the two series of in vitro measurements at the same location under steady-flow conditions.

was again excellent $\left(y=0.98 x+0.72, r^{2}=0.997\right.$, $\mathrm{SDE}=0.909 \mathrm{~mL} /$ cycle, $p=0.00$ ). Bland-Altman analysis (Fig. 6) showed that the difference between the two series is small (mean of $0.321 \mathrm{~mL} / \mathrm{cycle}$, standard deviation of $0.903 \mathrm{~mL} /$ cycle) and generally random throughout the range of flow conditions studied. A Mann-Whitney test confirmed the statistical agreement of the data $(p=0.90$, CI: [-19.86, $21.15 \mathrm{~mL} /$ cycle].

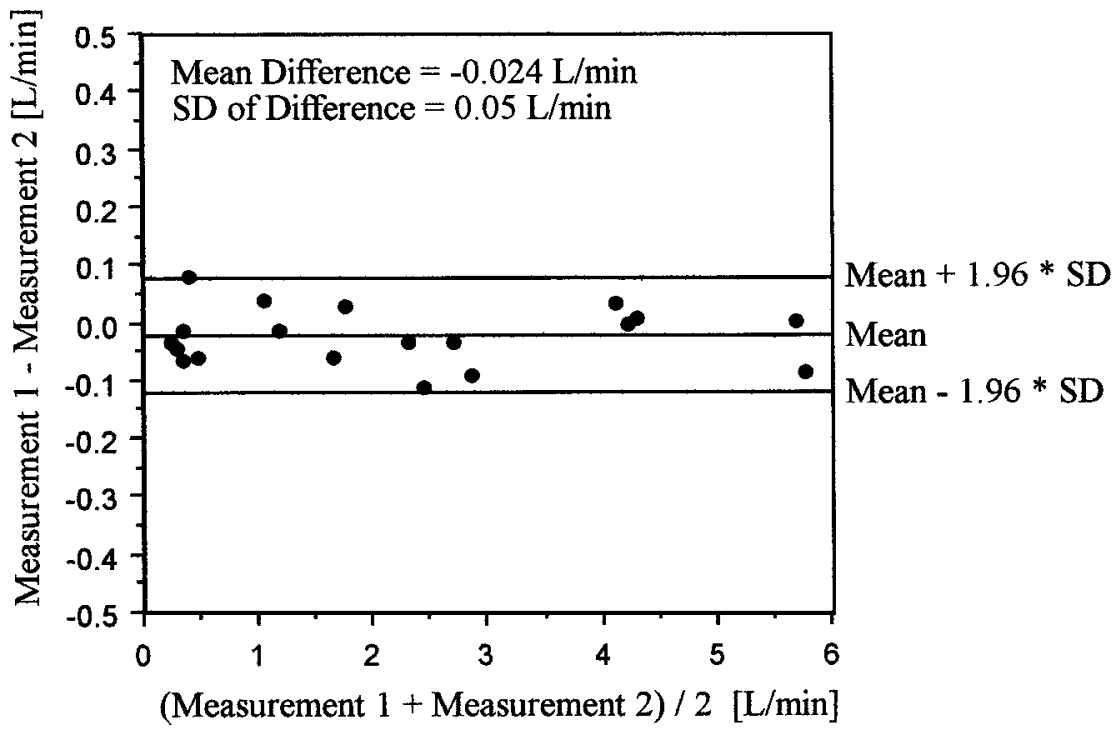

Figure 4. Bland-Altman graph showing the agreement between the two series of in vitro measurements at the same location under steady flow conditions: Notice the small mean and standard deviation of the differences between the two series of measurements. 


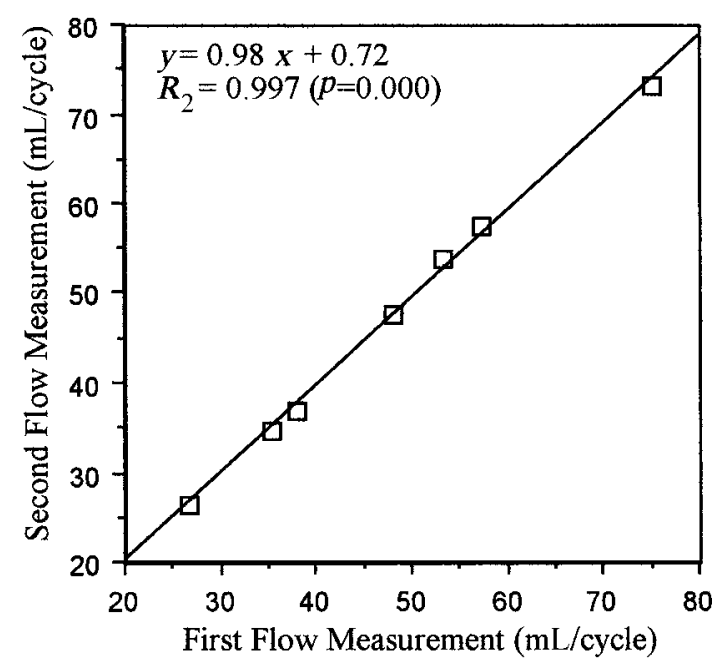

Figure 5. Correlation between the two series of in vitro measurements at the same location under pulsatile flow conditions.

\section{In Vivo}

Table 3 contains all the in vivo PVM results. Figure 7 shows the correlation between the two series of measurements. A very good correlation $(y=0.97 x+1.09$, $r^{2}=0.993, \quad \mathrm{SDE}=2.472 \mathrm{~mL} / \mathrm{beat}, \quad p=0.000$ ) was found. The agreement between the two series of measurements is also seen from the Bland-Altman analysis plot (Fig. 8) where the mean of their difference is very close to zero $(0.05 \mathrm{~mL} / \mathrm{beat})$ and the standard deviation of this difference is small $(2.48 \mathrm{~mL} / \mathrm{beat})$. The scattering of the differences between the two series is small and random throughout the flow rate range used. Statistical analysis with a Mann-Whitney test confirmed that there is no statistically significant difference between the two series ( $p=1.00$, confidence interval (CI): $[-28.29$, $25.12 \mathrm{~mL} /$ beat].

\section{DISCUSSION}

Magnetic resonance phase velocity mapping is currently a practical technique for blood flow measurements, based on the quality of the data acquired. Although the accuracy of PVM has been demonstrated in vitro, its clinical reliability depends on a combination of parameters, some of which are related to fluid mechanics. Since there is no gold standard for blood flow measurements in vivo, PVM needs to be clinically evaluated with a different approach. In a recent study, Bottini et al. (21) studied the potential of MRI to assess left ventricular mass. Although they evaluated the accuracy of MRI by comparing the results with direct ex vivo weight measurements of human hearts, they determined its precision in order to evaluate PVM in vivo. Precision was defined as the repeatability of sequential identical measurements during the same examination. The same pathway was followed in the present study, investigating the precision of PVM; in other words, we investigated the repeatability of identically taken

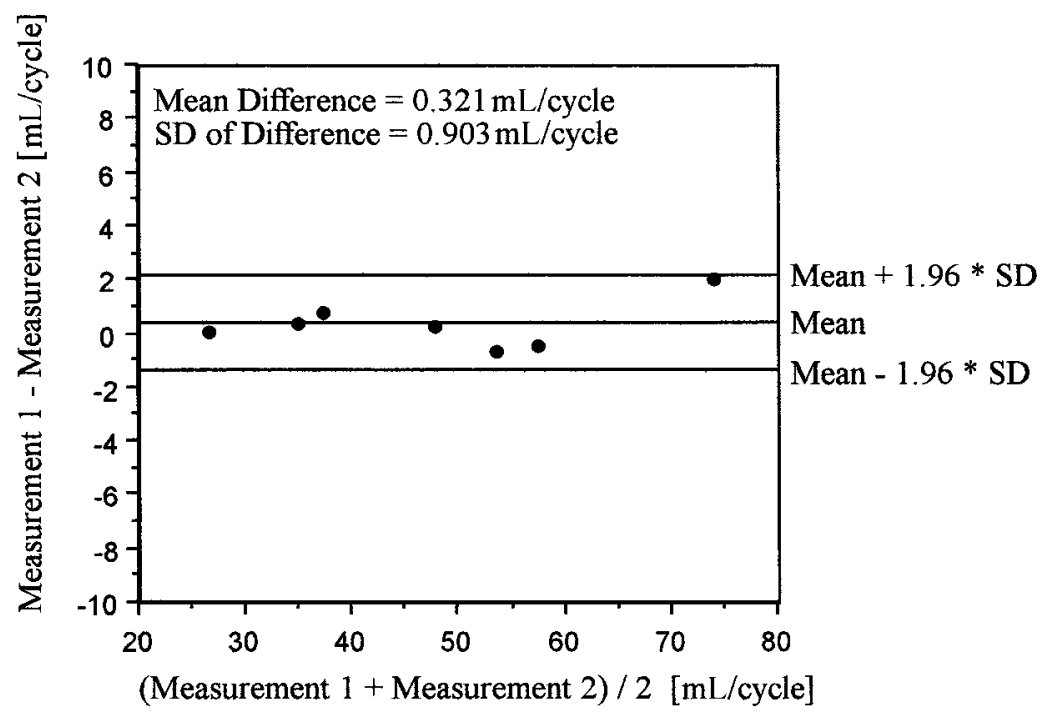

Figure 6. Bland-Altman graph showing the agreement between the two series of in vitro measurements at the same location under pulsatile flow conditions: Notice the small mean and standard deviation of the differences between the two series of measurements. 
Table 3

In Vivo PVM-Measured Flow Volumes

\begin{tabular}{llcc}
\hline Condition of Subject & $\begin{array}{c}\text { Measured } \\
\text { Quantity }\end{array}$ & $\begin{array}{c}\text { Measured } \\
\text { Series 1 } \\
\text { (mL/beat) }\end{array}$ & $\begin{array}{c}\text { Measured } \\
\text { Series 2 } \\
\text { (mL/beat) }\end{array}$ \\
\hline Mild AR (grade I) $_{\text {Mild AR (grade I) }}^{\text {aRV }}$ & 7.0 & 8.0 \\
Moderate AR (grade II) & ARV & 10.0 & 11.0 \\
Moderate-to-severe AR (grade III) & ARV & 17.0 & 16.0 \\
Moderate AR (grade II) & ARV & 22.0 & 21.0 \\
Moderate-to-severe AR (grade III) & ARV & 22.0 & 22.0 \\
Moderate-to-severe AR (grade III) & ARV & 39.0 & 39.0 \\
Healthy & ARV & 41.0 & 43.0 \\
Healthy & SV & 67.5 & 71.4 \\
Healthy & SV & 68.1 & 67.3 \\
\hline
\end{tabular}

${ }^{a}$ AR grades determined by angiography and Doppler echocardiography.

${ }^{b}$ ARV: Aortic regurgitant volume.

${ }^{\mathrm{c}} \mathrm{SV}$ : Stroke volume.

measurements. To characterize a technique as reliable, it needs to be both accurate and precise.

In this study, the precision was investigated both in vitro and in vivo. In vitro investigation of the precision of PVM was necessary regardless of the previously demonstrated accuracy of the technique in order to better evaluate the clinical data. A systematic experimental study was designed and performed using a variety of flow conditions. Subsequently, an in vivo study was performed measuring the flow in the ascending aorta. A number of subjects had aortic regurgitation, and this allowed for the evaluation of

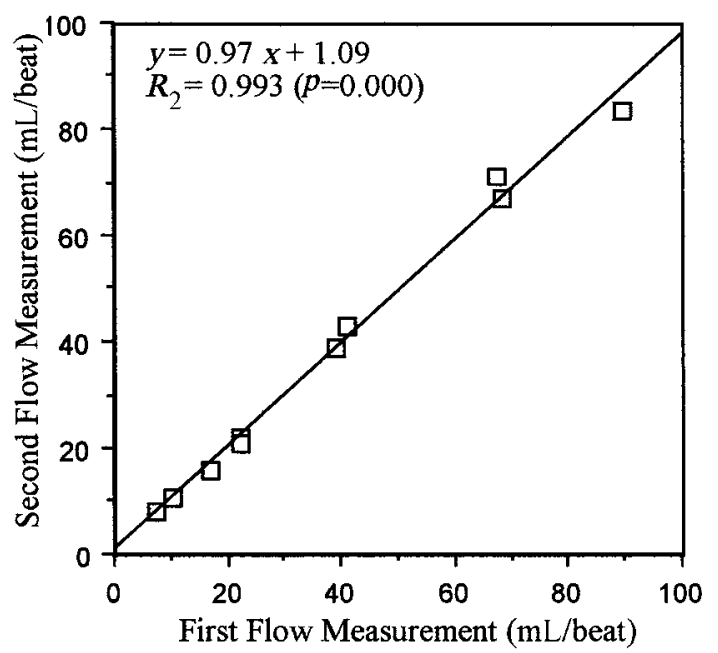

Figure 7. Correlation between the two series of in vivo measurements at the same location for each subject. the precision of PVM in measuring not only total stroke volumes but also the integral of the flow curves (regurgitant volume) over a specific part of the cardiac cycle (diastole). In the case of AR, reliable blood flow information is essential to better monitor the progress of the disease and to determine quantitatively the effectiveness of vasodilators used for pharmacologic treatment.

The very high precision found in vitro was the reference point for the clinical measurements. The pulsatile flow results were of great importance because the flow conditions generated approached the physiologic flow environment. The in vivo results showed very high repeatability, comparable to the experimental. This is of great significance, considering that the in vivo situation involves factors that are impossible to control and often not predicted. This shows the great potential of PVM to provide reliable in vivo flow measurements.

This study has a number of limitations. Although the flow rate was varied to cover an extensive range, there was no simulation of complex flow fields, including vortices or flow acceleration. Simulating a flow environment with very disturbed flow would not be very useful at this stage, because the reproducibility of such an environment for repeatable measurements would be difficult and because PVM could not provide reliable results. Nevertheless, future approaches in examining a variety of flow fields would provide additional information about the degree of precision of PVM.

All sources of error present in all MRI procedures (artifacts from blood motion, cardiac motion, respiratory motion, cardiac arrhythmia, and patient motion) could 


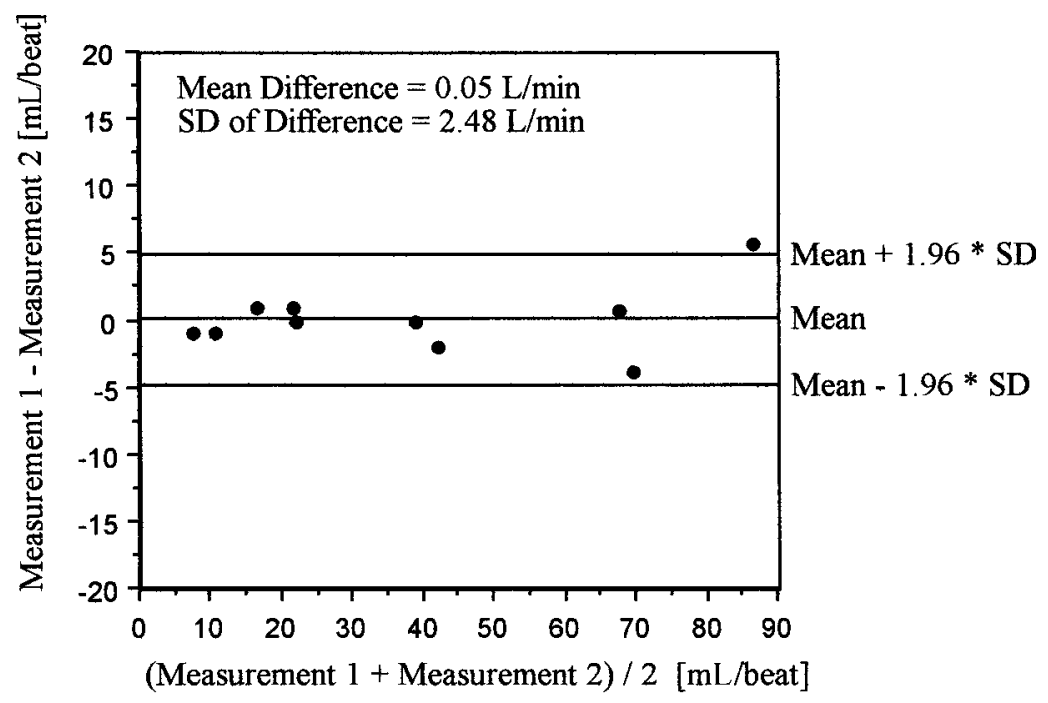

Figure 8. Bland-Altman graph showing the agreement between the two series of in vivo measurements at the same location for each subject. Notice the small mean and standard deviation of the differences between the two series of measurements.

introduce errors in the implementation of PVM, and they also need to be studied. In the in vivo part of this study, the measurements were taken at a location where the throughplane velocity-encoded measurements may be affected by cardiac and respiratory motion. Correction procedures have lately been proposed (22), and this could improve the accuracy of these measurements. However, this study focused on the precision of PVM. The precision of PVM should not be affected by standard errors (e.g., cardiac motion), as they will equally affect successive PVM measurements taken under similar conditions. So, although these errors may affect the accuracy, they should not affect the precision (repeatability). This is clearly shown in this study. Further systematic studies will provide additional information about the degree of motion errors and how to reduce or even eliminate their effects on the velocity measurements. Nevertheless, the results of this study show clearly that PVM is very robust as a flow quantification technique; any possible errors from motion are not linked to its ability to measure flow. Stronger conclusions about these effects could be drawn from a large amount of clinical data, from which more information could be obtained to improve the reliability of PVM clinically.

\section{CONCLUSION}

This study investigated the precision of magnetic resonance phase velocity mapping in measuring blood flow.
The precision of PVM, that is the repeatability of identically acquired successive measurements, both in vitro and in vivo, was found to be very high. In the absence of a clinical gold-standard technique for flow measurements with which PVM could be compared to determine accuracy, the precision is a strong determinant of the reliability of PVM in quantifying blood flow.

\section{ABBREVIATIONS}

PVM Magnetic resonance phase velocity mapping

AR Aortic regurgitation

SDE Standard deviation of error

CI Confidence interval

ST Slice thickness

FOV Field of view

TR Repetition time

TE Echo time

VENC Velocity encoding value

\section{ACKNOWLEDGMENTS}

This work was supported by grants from the American Heart Association, Georgia Affiliate, the Emory/Georgia Tech Biomedical Technology Research Center, and the National Heart Lung and Blood Institute (R01 HL58147). 


\section{REFERENCES}

1. Moran, P.R. A flow Velocity Zeugmatographic Interlace for NMR Imaging in Humans. Magn. Reson. Imaging 1982, 1, 197-203.

2. Bryant, D.J.; Payne, J.A.; Firmin, D.N.; Longmore, D.B. Measurement of Flow with NMR Imaging Using a Gradient Pulse and Phase Difference Technique. J. Comput. Assist. Tomogr. 1984, 8, 588-93.

3. Bendel, P.; Buonocore, E.; Bockisch, A.; Besozzi, M.C. Blood Flow in the Carotid Arteries: Quantification by Using Phase-Sensitive MR Imaging. AJR 1989, 152, 1307-10.

4. Chatzimavroudis, G.P.; Walker, P.G.; Oshinski, J.N.; Franch, R.H.; Pettigrew, R.I.; Yoganathan, A.P. Slice Location Dependence of Aortic Regurgitation Measurements with MR Phase Velocity Mapping. Magn. Reson. Med. 1997, 37, 545-51.

5. Chatzimavroudis, G.P.,; Walker, P.G.; Oshinski, J.N.; Franch, R.H.; Pettigrew, R.I.; Yoganathan, A.P. The Importance of Slice Location on the Accuracy of Aortic Regurgitation Measurements with Magnetic Resonance Phase Velocity Mapping: An In Vitro Investigation. Ann. Biomed. Eng. 1997, 25, 644-52.

6. Pettigrew, R.I.; Dannels, W.; Galloway, J.R.; Pearson, T.; Millikan, W.; Henderson, J.M.; Peterson, J.; Bernardino, M.E. Quantitative Phase-Flow MR Imaging in Dogs by Using Standard Sequences: Comparison with In Vivo Flow-Meter Measurements. AJR 1987, 148, 41114.

7. Meier, D.; Maier, S.; Bosiger, P. Quantitative Flow Measurements on Phantoms and on Blood Vessels with MR. Magn. Reson. Med. 1988, 8, 25-34.

8. Mohiaddin, R.H.; Wann, S.L.; Underwood, R.; Firmin, D.N.; Rees, S.; Longmore, D.B. Vena Caval Flow: Assessment with Cine MR Velocity Mapping. Radiology 1990, 177, 537-41.

9. Pelc, L.R.; Pelc, N.J.; Rayhill, S.C.; Castro, L.J.; Glover, G.H.; Herfkens, R.J.; Miller, D.C.; Jeffrey, R.B. Arterial and Venous Blood Flow: Noninvasive Quantification with MR Imaging. Radiology 1992, 185, 809812.

10. Dulce, M.-C.; Mostbeck, G.H.; O’Sullivan, M.; Cheitlin, M.; Caputo, G.R.; Higgins, C.B. Severity of Aortic Regurgitation: Interstudy Reproducibility of Measurements with Velocity-Encoded Cine MR Imaging. Radiology 1992, 185, 234-40.

11. Honda, N.; Machida, K.; Hashimoto, M.; Mamiya, T.; Takahashi, T.; Kamano, T.; Kashimada, A.; Inoue, Y.; Tanaka, S.; Yoshimoto, N.; Matsuo, H. H. Aortic
Regurgitation: Quantitation with MR Imaging Velocity Mapping. Radiology 1993, 186, 189-94.

12. Søndergaard, L.; Hildebrandt, P.; Lindvig, K.; Thomsen, C.; Stahlberg, F.; Kassis, E.; Henriksen, O. Valve Area and Cardiac Output in Aortic Stenosis: Quantification by Magnetic Resonance Velocity Mapping. Am. Heart J. 1993, $126,1156-64$.

13. Underwood, S.R.; Firmin, D.N.; Klipstein, R.H.; Rees, R.S.O.; Longmore, D.B. Magnetic Resonance Velocity Mapping: Clinical Application of a New Technique. Br. Heart J. 1987, 57, 404-412.

14. Klipstein, R.H.; Firmin, D.N.; Underwood, S.R.; Rees, R.S.O.; Longmore, D.B. Blood Flow Patterns in the Human Aorta Studied by Magnetic Resonance. B. Heart J. 1987, 58, 316-23.

15. Kondo, C.; Caputo, G.R.; Semelka, R.; Foster, E.; Shimakawa, A.; Higgins, C.B. Right and Left Ventricular Stroke Volume Measurements with Velocity-Encoded Cine MR Imaging: In-Vitro and In-Vivo Validation. AJR 1991, 157, 9-16.

16. Kilner, P.J.; Yang, G.Z.; Mohiaddin, R.H.; Firmin, D.N.; Longmore, D.B. Helical and Retrograde Secondary Flow Patterns in the Aortic Arch Studied by Three-Directional Magnetic Resonance Velocity Mapping. Circulation 1993, 88, 2235-47.

17. Bogren, H.G.; Buonocore, M.H. Blood Flow Measurements in the Aorta and Major Arteries with MR Velocity Mapping. Magn. Reson. Imaging 1994, 4, 119-30.

18. Chatzimavroudis, G.P.; Oshinski, J.N.; Franch, R.H.; Pettigrew, R.I.; Walker, P.G.; Yoganathan, A.P. Quantification of Aortic Regurgitation with Magnetic Resonance Phase Velocity Mapping: A Clinical Investigation of the Importance of Slice Location. J. of Heart Valve Disease 1998, 7, 94-101.

19. Hines, W.W.; Montgomery, D.C. Probability and Statistics in Engineering and Management Science, 3rd Ed.; John Wiley \& Sons: New York, 1990.

20. Bland, J.M.; Altman, D.G. Statistical Methods for Assessing Agreement Between Two Methods of Clinical Measurements. Lancet 1986, 1, 307-310.

21. Bottini, P.B.; Carr, A.A.; Prisant, L.M.; Flickinger, F.W.; Allison, J.D.; Gottdiener, J.S. Magnetic Resonance Imaging Compared to Echocardiography to Assess Left Ventricular Mass in Hypertensive Patients. Am. J. Hypertens. 1995, 8, 221-28.

22. Chuang, M.L.; Chen, M.H.; Khasgiwala, V.C.; McConnell, M.V.; Edelman, R.R.; Manning, W.J. Adaptive Correction of Imaging Plane Position in Segmented K-Space Cine Cardiac MRI. Magn. Reson. Imaging 1997, 7, 811-14. 
Copyright $\odot 2002$ EBSCO Publishing 
Copyright of Journal of Cardiovascular Magnetic Resonance (Taylor \& Francis Ltd) is the property of Taylor \& Francis Ltd and its content may not be copied or emailed to multiple sites or posted to a listserv without the copyright holder's express written permission. However, users may print, download, or email articles for individual use. 